\title{
A Role for Polymodal C-Fiber Afferents in Nonhistaminergic Itch
}

\author{
Lisa M. Johanek, ${ }^{1}$ Richard A. Meyer ${ }^{1,3}$ Robert M. Friedman, ${ }^{4}$ Kenneth W. Greenquist, ${ }^{4}$ Beom Shim, ${ }^{1}$ Jasenka Borzan, ${ }^{1,2}$ \\ Tim Hartke, ${ }^{1}$ Robert H. LaMotte, ${ }^{4}$ and Matthias Ringkamp ${ }^{1}$ \\ Departments of ${ }^{1}$ Neurosurgery and ${ }^{2}$ Anesthesiology, Johns Hopkins University, Baltimore, Maryland 21287, ${ }^{3}$ The Applied Physics Laboratory, Johns \\ Hopkins University, Laurel, Maryland 20723, and ${ }^{4}$ Department of Anesthesiology, Yale University, New Haven, Connecticut 06520
}

Recent psychophysical and electrophysiological studies in humans suggest the existence of two peripheral pathways for itch, one that is responsive to histamine and a second pathway that can be activated by nonhistaminergic pruritogens (e.g., cowhage spicules). To explore the peripheral neuronal pathway for nonhistaminergic itch, behavioral responses and neuronal activity in unmyelinated afferent fibers were assessed in monkey after topical application of cowhage spicules or intradermal injection of histamine and capsaicin. Cowhage and histamine, but not capsaicin, evoked scratching behavior indicating the presence of itch. In single-fiber recordings, cowhage, histamine and/or capsaicin were applied to the cutaneous receptive field of 43 mechano-heat-sensitive C-fiber (CMH) nociceptors. The majority of CMHs exhibited a prolonged response to cowhage (39 of 43) or histamine (29 of 38), but not to capsaicin (3 of 34). Seven CMHs were activated by cowhage but not histamine. The average response to cowhage was more than twice the response to histamine, and responses were not correlated. The response of the CMHs to a stepped heat stimulus $\left(49^{\circ} \mathrm{C}, 3 \mathrm{~s}\right)$ was either quickly adapting $(\mathrm{QC})$ or slowly adapting (SC). In contrast, the cowhage response was characterized by bursts of two or more action potentials $(\mathrm{at} \sim 1 \mathrm{~Hz})$. The total cowhage response of the QC fibers ( 97 action potentials $/ 5 \mathrm{~min}$ ) was twice that of the $\mathrm{SC}$ fibers ( 49 action potentials $/ 5 \mathrm{~min}$ ). A subset of QC fibers exhibited high-frequency intraburst discharges $(\sim 30 \mathrm{~Hz})$. These results suggest multiple mechanisms by which CMHs may encode itch to cowhage as well as pain to mechanical and heat stimuli.

Key words: pruritus; cowhage; nociceptor; capsaicin; pain; unmyelinated

\section{Introduction}

Although a neural pathway for histamine-induced itch has been identified, the neuronal mechanisms underlying nonhistaminergic itch are poorly understood. In humans, a population of C-fiber mechanically insensitive (CMi) afferents is thought to mediate the sensation of histamine-induced itch (Schmelz et al., 1997, 2003). The histamine-induced neuronal activity in these CMi afferents matched the time course of the itch sensation, and their large cutaneous receptive fields could account for the large area of histamine-induced flare (Schmelz et al., 1997).

Multiple lines of evidence suggest that additional afferent fibers must play a role in the sensation of itch. For example, itch can be produced by mechanical (von Frey, 1922; Shelley and Arthur, 1957) and electrical (Ikoma et al., 2005) stimuli that are unlikely to activate CMi afferents. Itch can also be produced in the absence of a flare response (Ikoma et al., 2005). Moreover, although histamine produces a reliable itch sensation in healthy subjects, histamine does not appear to be the pruritogen in a

Received Dec. 21, 2007; revised June 13, 2008; accepted June 14, 2008.

This work was supported by National Institutes of Health Grant P01 NS 47399. We thank Steve Davidson, Glenn Giesler, Hermann Handwerker, Barbara Namer, Raf Schepers, and Martin Schmelz for critically reading a previous draft of this manuscript.

Correspondence should be addressed to Matthias Ringkamp, Department of Neurosurgery, School of Medicine, Johns Hopkins University, Meyer 5-109, 600 North Wolfe Street, Baltimore, MD 21287. E-mail: platelet@jhmi.edu. DOI:10.1523/JNEUROSCI.1760-08.2008

Copyright $\odot 2008$ Society for Neuroscience $\quad 0270-6474 / 08 / 287659-11 \$ 15.00 / 0$ number of dermatological and chronic itch conditions (Twycross et al., 2003). Many of these diseases are unresponsive to antihistamine treatment, suggesting the involvement of nonhistaminergic mechanisms.

Mucuna pruriens (cowhage), a plant found in tropical regions, produces pod-like structures covered with spicules that cause itch when inserted superficially into human skin (Shelley and Arthur, 1955b, 1957) and has been shown to activate most C-polymodal nociceptive nerve fibers in the cat (Tuckett and Wei, 1987b). Cowhage-induced itch is thought to be of nonhistaminergic origin (Shelley and Arthur, 1955a,b), and topical application of antihistamines blocks histamine- but not cowhage-induced itch (Johanek et al., 2007). In contrast to histamine, cowhage does not produce a large area of flare. In addition, the magnitude of itch produced by cowhage is not correlated with that produced by histamine (Johanek et al., 2007). Recent microneurography studies in humans show that mechano-heat-sensitive C-fibers (CMHs), but not CMi afferents, are excited by cowhage (Namer et al., 2008). However, because painful stimuli also activate mechanosensitive C-fibers, it is unclear how the CNS interprets the input from these afferents as "itch" or "pain." One potential solution to this problem would be if a subtype of mechanosensitive C-fibers existed that is particularly responsive to cowhage. It is currently unknown, however, if such a subtype exists. Based on the response to a short duration suprathreshold heat stimulus, mechanosensitive C-fibers in monkey can be classified as quickly 
(QC) or slowly adapting (SC) (Meyer and Campbell, 1981). In addition, QC fibers have lower mechanical and heat thresholds than SC fibers (Meyer and Campbell, 1981). We therefore hypothesized that QC and SC fibers also differ in their responses to cowhage.

In the present study, we evaluated the behavioral responses of monkey to the application of cowhage spicules, histamine, capsaicin, and their appropriate controls. We then tested the responsiveness of cutaneous unmyelinated afferent fibers to these stimuli in electrophysiological experiments.

\section{Materials and Methods}

\section{Behavioral experiments}

Three monkeys (Macaca fascicularis, 5-7 kg) were used in these studies performed at Yale University to test the behavioral responses to cowhage, histamine, and capsaicin. Several days before behavioral testing, both lower legs were shaved. On the day of the test, a video camera was set up in front of the cage in a room where a small group of monkeys was housed. The monkey was squeezed to the front of the cage and slightly manipulated such that one type of active agent (spicules or intradermal injection of histamine or capsaicin) could be applied to the side and the midportion of one lower leg and, concurrently, the control for that agent to the homologous site on the other leg. Capsaicin [100 $\mu \mathrm{g}$, dissolved in a Tween 80-saline solution as described previously (LaMotte et al., 1991)] and histamine ( $20 \mu \mathrm{g}$ in saline) were injected intradermally. Cowhage spicules were applied by pressing a cowhage pod against the skin. A Tween 80-saline solution, saline, and heat-inactivated cowhage pods served as respective control stimuli. For each of three monkeys, each agent (and its control) was tested once at intervals of at least 2 weeks. After an agent and its control had been applied to a monkey, the video recording was started and the monkey released into the cage. The experimenter immediately left the room. Video recording was terminated after $30 \mathrm{~min}$, at which time cowhage- and histamine-induced itch or capsaicin-evoked pain had dissipated as tested in humans (Simone et al., 1987; LaMotte et al., 1991; Masood et al., 2005). After completion of the studies, video recordings were used to count the number of scratches applied to either leg during the observation period. Other behaviors that might occur much less often, such as rubbing or picking the active site, were not counted, as were behaviors that were not site specific, i.e., directed toward other parts of the body. Although the scratching movements might be interpreted as clustered into "bouts," we did not analyze them as such, but rather counted each individual scratch. Stimulus application and analysis of the video recording were performed under blinded conditions.

\section{Electrophysiological experiments}

General procedures. A separate group of nine monkeys (Macaca fascicularis, $4-6 \mathrm{~kg}$ ) was used for the electrophysiological recordings performed at Johns Hopkins University. Different nerves innervating the hairy skin of the limbs were used. Only one nerve was studied per experimental session, and sessions were separated by at least 2 weeks. Animals were initially sedated by intramuscular ketamine $(12 \mathrm{mg} / \mathrm{kg}$ with $0.04 \mathrm{mg} / \mathrm{kg}$ atropine) and anesthesia was induced by an intravenous bolus injection of sodium pentobarbital $(6 \mathrm{mg} / \mathrm{kg})$ and maintained by constant infusion $(4-6 \mathrm{mg} / \mathrm{kg} / \mathrm{h})$ thereof. Hydration was maintained with a continuous infusion of $5 \%$ dextrose in physiological saline solution $(4-6 \mathrm{mg} / \mathrm{kg} / \mathrm{h})$. An intramuscular injection of penicillin $(600,000 \mathrm{U})$ was given for prophylaxis against infection. Intubation was performed, and animals were paralyzed with an intravenous dose of pancuronium bromide $(0.1 \mathrm{mg} /$ $\mathrm{kg}$ ) every $2 \mathrm{~h}$ or when necessary. Ventilation was adjusted throughout the experiment to maintain the expired $\mathrm{pCO} 2$ within physiological range (i.e., $35-45 \mathrm{mmHg}$ ). Heart rate was monitored by an electrogardiogram to ensure an adequate level of anesthesia. Supplemental doses of pentobarbital were administered if the heart rate increased by $>10 \%$ after application of noxious stimuli. Core temperature was monitored via a rectal thermometer and maintained near $38^{\circ} \mathrm{C}$ with feedback-controlled circulating water heating pads.

Teased-fiber recording techniques (Campbell and Meyer, 1983) were used to record from nerves innervating the hairy skin. Single primary afferent fibers from the saphenous, superficial peroneal, sural, superficial radial, and medial antebrachial cutaneous nerves were isolated and studied. Briefly, small filaments were cut proximally from the cutaneous nerve and placed on a dissecting platform. A smaller strand was dissected from the filament and looped around a silver-wire recording electrode. A tripolar nerve-stimulating electrode was placed on the whole nerve $\sim 40$ $\mathrm{mm}$ distal to the recording electrode. This distal electrode was used to stimulate the nerve trunk to reveal the fibers on the recording electrode.

Receptive field mapping. Once a single fiber was identified by distal stimulation of the nerve trunk, the receptive field of the fiber was identified. First, the skin was squeezed gently to identify mechanically sensitive afferent fibers. A von Frey hair of 8.6 bar (corresponding to $8.6 \times 10^{6}$ $\mathrm{dyn} / \mathrm{cm}^{2}$ ) was used to map the receptive field of mechanically sensitive afferents, whereas a 12 bar von Frey was used to map the receptive field of CMi afferents when possible. A colored marker was used to delineate the receptive field.

For some CMi units, a mechanical receptive field could not be identified. In these cases, an electrical search paradigm was used (Meyer et al., 1991). In brief, a saline-soaked cotton swab was used to deliver transcutaneous electrical stimuli (up to $100 \mathrm{~mA}, 2 \mathrm{~ms}$ duration), and a needle inserted into the distal skin served as the return electrode. The cotton swab was moved distally along the course of the peripheral nerve, and the conduction latency was monitored. When the electrical receptive field was encountered, the electrical threshold reached a minimum, the conduction latency at threshold reached a maximum, and the conduction latency decreased in discrete steps ("hopping") as stimulus intensity increased (for more details, see Peng et al., 1999). The electroreceptive field was defined by those locations where discrete steps in latency were observed.

The conduction distance was measured along the assumed course of the nerve from the recording electrode to the middle of the receptive field. The conduction velocity was calculated by dividing this distance by the conduction latency obtained at least $1.5 \times$ threshold for excitation. Fibers with a conduction velocity of $<2 \mathrm{~m} / \mathrm{s}$ were regarded as C-fibers.

Measuring the mechanical threshold. After the receptive field was mapped, a highly sensitive mechanically responsive spot in the receptive field was localized using a suprathreshold von Frey filament. This spot was marked with a felt-tipped pen. After a 2 min rest period, an ascending series of von Frey probes was applied to the hot spot to determine mechanical threshold, which was defined as the smallest probe producing activity in two of four stimulus applications. If the mechanical threshold was $\geq 6$ bar, the fiber was classified as a CMi (Meyer et al., 1991). Strong mechanical stimuli (strong von Frey hairs, forceps pinch, or needle insertion) can sometimes activate mechanically insensitive afferents. However, these stimuli were not routinely used to characterize the fibers to avoid damaging the skin and the afferent fibers.

Testing the responsiveness to cold and heat. Fibers were tested for their responsiveness to cold stimuli by application of a 15-mm-diameter copper brass bar that had either been refrigerated or placed in a freezer. An identical plastic probe of the same diameter and weight at room temperature was used to control for responses associated with the pressure of the probe. Heat stimuli were delivered to the receptive field in a contact-free manner using a radiometer feedback-controlled carbon dioxide laser (Meyer et al., 1976). To test for heat sensitivity, a $49^{\circ} \mathrm{C}, 3 \mathrm{~s}$ stimulus was applied to the receptive field from a baseline temperature of $38^{\circ} \mathrm{C}(3 \mathrm{~s})$. When receptive fields were larger than the laser diameter $(8 \mathrm{~mm})$, the unit was tested multiple times in adjacent but nonoverlapping areas. The $49^{\circ} \mathrm{C}, 3 \mathrm{~s}$ stimulus allowed CMHs to be classified as QC or SC fibers (Meyer and Campbell, 1981). As illustrated in the specimen recording of Figure $2 B$, QC fibers discharge with a high peak frequency in the first second of such a stimulus, but the response adapts during maintained stimulation. In contrast, the response of SC fibers (see Fig. 2B), is steady throughout the stimulus. The response of both QC and SC fibers adapted for long duration (30 s) heat stimuli (Meyer and Campbell, 1981). If fibers responded to the $49^{\circ} \mathrm{C}, 3 \mathrm{~s}$ stimulus, a heat staircase was applied 10 min later to determine heat threshold. The $10 \mathrm{~min}$ waiting period between heat stimuli was used to allow full recovery from fatigue that can be observed with repetitive heat stimulation at short intervals (LaMotte and 
Campbell, 1978; Slugg et al., 2000; Peng et al., 2003). The staircase began at a baseline temperature (normally $38^{\circ} \mathrm{C}$, but occasionally 33 or $35^{\circ} \mathrm{C}$ if the unit responded to the $38^{\circ} \mathrm{C}$ baseline given before the $49^{\circ} \mathrm{C}, 3 \mathrm{~s} \mathrm{stim}-$ ulus) and increased in $1^{\circ} \mathrm{C}, 1 \mathrm{~s}$ increments until reaching the final temperature of $49^{\circ} \mathrm{C}$. Threshold was defined as the temperature that evoked the first action potential (AP) followed by a response at the next temperature.

Cowhage preparation. Dried cowhage pods (Mucuna pruriens) were kindly provided by Zandu Pharmaceuticals. Some pods were autoclaved to produce spicules that no longer induce itch in humans (Johanek et al., 2007), and these heat-inactivated spicules served as controls. For the majority of experiments, cowhage spicules were delivered via different artificial applicators which would facilitate targeting of the receptive field of the unit under study. For the trials in a given fiber, only one type of applicator was used. Spicules were visualized under a dissecting microscope, pulled off of the pod, and inserted one by one onto either a moistened $5 \times 5 \mathrm{~mm}$ piece of Biore face pad or a cotton-tipped applicator that had been freshly painted with nail polish. The Biore pad and the nail polish held the base of the spicule, but the majority of spicules were released when the applicator was pressed against the skin. Approximately 15-20 spicules could be loaded onto the Biore pads, whereas $\sim 30-40$ spicules were loaded onto each nail polish applicator. Of all the $\mathrm{CMH}$ experiments, $30 \%$ were done using the Biore pads, whereas $56 \%$ were performed with the cotton swab applicators. In $14 \%$ of the experiments, a cowhage pod itself was pressed to the skin. In five single unit recordings, a single spicule was inserted into the receptive field as described below.

Histamine and capsaicin preparation. Capsaicin (Sigma-Aldrich) was prepared in a vehicle of Tween 80 and saline as described previously (LaMotte et al., 1991) to deliver a dose of $10 \mu \mathrm{g}$ in a $10 \mu \mathrm{l}$ volume. Histamine dihydrochloride (Sigma-Aldrich) was prepared in a saline vehicle. A dose of either $1 \mu \mathrm{g} / 10 \mu \mathrm{l}$ or $10 \mu \mathrm{g} / 10 \mu \mathrm{l}$ was administered. At these doses, intradermal injection of capsaicin and histamine produce the sensation of pain and itch, respectively, in human subjects (Simone et al., 1987; LaMotte et al., 1991).

Experimental protocol. After a fiber was identified, mapped, and characterized as described above, a standard protocol was used to determine the fiber's responsiveness to various pruritic and algogenic stimuli. A majority of $\mathrm{CMH}$ ( 34 of 43) and CMi nociceptors ( 5 of 5) received at least one application of all substances (inactive cowhage, cowhage, saline, histamine, capsaicin vehicle, and capsaicin). Responses to all substances were not obtained for nine $\mathrm{CMHs}$ because of a poor signal-to-noise ratio or loss of the fiber, but each of these fibers was tested with cowhage. Before application of spicules or injection of chemicals, baseline activity was always recorded for $1 \mathrm{~min}$. For $32 \mathrm{CMHs}$, the recording of chemicalevoked activity lasted for at least $5 \mathrm{~min}$. In $11 \mathrm{CMH}$ and $3 \mathrm{CMi}$ units, recordings were performed to, maximally, $20 \mathrm{~min}$, with the restriction that, $5 \mathrm{~min}$ after stimulus application, the recording could be stopped anytime when no neuronal activity had been observed for $3 \mathrm{~min}$.

In initial studies $(n=10)$, inactive cowhage spicules were applied once to the receptive field, followed by a single active cowhage application. However, because responses to cowhage were quite variable (see Results) both inactive and active cowhage spicules were each applied to the receptive field three times in the following 14 studies. Because inactive spicules rarely caused activity (see Results), inactive cowhage spicules were applied to the receptive field only once in later studies $(n=19)$, followed by three applications of active cowhage spicules. Active cowhage was tested at least twice in all CMi afferents. Before insertion of the spicules, baseline activity was recorded for $1 \mathrm{~min}$. Spicules were then inserted into the skin over a $15 \mathrm{~s}$ time period and aimed toward the mechanosensitive areas of the receptive field. The number of spicules sticking into the receptive field was counted by two experimenters with the aid of a microscope. Spicules were removed from the skin with tape between trials. At least a 2 min wait separated the removal of the cowhage spicules from the subsequent stimulus trial. In five nerve fibers responsive to cowhage, we attempted to test the response to the application of a single spicule into the receptive field. The spicule was held with forceps and pushed into the skin at a spot identified previously to be highly sensitive to mechanical stimuli.

After testing with cowhage, the typical order of subsequent injection into the receptive field was as follows: saline $(10 \mu \mathrm{l})$, histamine $(1 \mu \mathrm{g} / 10$ $\mu \mathrm{l}$ or $10 \mu \mathrm{g} / 10 \mu \mathrm{l})$, capsaicin vehicle $(10 \mu \mathrm{l})$, and capsaicin $(10 \mu \mathrm{g} / 10 \mu \mathrm{l})$. A least a 2 min wait occurred between the end of the response to one agent and the start of the baseline recording before the administration of the next agent.

Definition of responders. Units were classified as "responders" to a pruritogenic or algogenic stimulus if at least $10 \mathrm{APs}$ were observed within 5 min after stimulus application, and the number of action potentials was at least twice that in response to the inactive substance. The rationale for a minimum of 10 action potentials is based on our observation that in $75 \%$ of the fibers tested, the response to inactive cowhage was $<10$ action potentials per $5 \mathrm{~min}$. In practice, the smallest response of a fiber classified as a responder was 14 action potentials. To ensure that the response to active cowhage is substantially greater than the response to inactive spicules, we stipulated that the response to active spicules had to be at least twice the response to inactive spicules. (A less stringent criterion of $1.5 \times$ led to same number of responders; a $2.5 \times$ criterion led to two fewer fibers being counted as responders.)

The baseline activity recorded $1 \mathrm{~min}$ before stimulus application was subtracted from the neuronal activity observed in each minute after stimulus application. This occasionally led to a "negative" response, i.e., the spontaneous activity during the baseline was greater than the activity in the $5 \mathrm{~min}$ after stimulus application. Fibers tested with three cowhage applications were classified as responders or nonresponders based on their maximum cowhage response. The rationale to use the maximum response instead of the median was that some units with a clear response to cowhage in one of the trials would have been falsely classified as nonresponders when the median response was used. Furthermore, we wanted to compare responses to the intradermal injections of the different agents with the cowhage responses. For injections, volumes of $10 \mu \mathrm{l}$ were administered intradermally thereby exposing many receptive endings to the substances and thereby maximizing excitation. In contrast, because of their small tip size $(1-10 \mu \mathrm{m})$ (Shelley and Arthur, 1957), cowhage spicules deliver a stimulus to a much smaller area of the receptive field, and the observed response variability in a given fiber (see Results) suggests that spicules have to be inserted closely to receptive terminals.

Data collection and analysis. A personal computer with a computerbased data acquisition board and customized data acquisition and analysis software (DAPSYS; Brian Turnquist, Bethel University, St. Paul, MN; see www.dapsys.net) was used to display, record, and store action potential activity. On- and off-line action potential discrimination could be performed using DAPSYS. The different phases of the cowhage application and injection protocols were timed by DAPSYS, which provided an auditory signal at the start of the baseline recording, application time, needle insertion, and the injection of substances. Action potentials recorded on DAPSYS and the corresponding events or manipulations were time stamped to allow for direct correlation between the two. DAPSYS also controlled the laser thermal stimulator.

Data are presented as mean \pm SEM. The type of statistical analysis used (parametric versus nonparametric) was dependent on the particular data set being analyzed as indicated in the text. When appropriate, corrections were performed for multiple testing as indicated in the text.

\section{Results}

\section{Cowhage and histamine produce scratching behavior in monkey}

Studies were performed in three monkeys to investigate the behavioral responses induced by cowhage spicules, histamine, and capsaicin. In humans, histamine and cowhage mainly cause the sensation of itch, i.e., the desire to scratch. In contrast, capsaicin injection produces a burning pain sensation in humans. To quantify the behavior in monkey, the number of scratches over the observation period (30 $\mathrm{min})$ was counted. A high number of scratches was observed after the application of histamine and cowhage (Fig. 1). The monkeys typically used the contralateral hand to scratch the site of active cowhage application unless the cowhage was delivered, as it was in a few cases, to the lateral side 


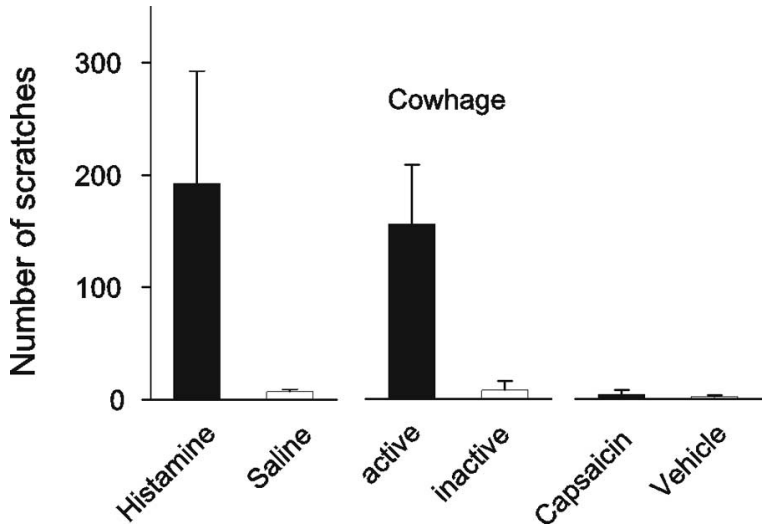

Figure 1. Cutaneous administration of histamine and active cowhage spicules induces scratching behavior in monkey $(n=3)$. Scratching was not observed after the application of saline, inactive cowhage spicules, or capsaicin and its vehicle. The number of scratches was counted by a blinded observer for 30 min after stimulus application. Error bars indicate mean \pm SEM.

of the leg, in which case the ipsilateral hand was used. The animals did not use the leg to scratch. Scratching, consisted of a series of flexing motions of the fingernails against the pruritic site. In contrast, a much lower number of scratches occurred after the application of the appropriate controls (saline, inactive spicules) and after the application of capsaicin or its vehicle (Fig. 1). We conclude that cowhage and histamine produce the sensation of itch in monkeys, and that nonhuman primates are therefore a suitable model to investigate the neuronal mechanisms underlying the sensation of cowhage- and histamine-induced itch.

\section{Mechano-heat-sensitive C-fibers}

We recorded from $43 \mathrm{CMHs}$ that were responsive to mechanical (threshold, $1.9 \pm 0.1$ bar) and heat stimuli (threshold, $42.9 \pm$ $0.4^{\circ} \mathrm{C}$ ), and they had an average conduction velocity of $0.83 \pm$ $0.02 \mathrm{~m} / \mathrm{s}$. The majority of units (38 of 43) were also cold responsive, displaying a response to application of a cold brass rod, but little or no response to the blunt pressure of a plastic-covered brass rod of the same weight.

$\mathrm{CMH}$ show two types of responses to a $3 \mathrm{~s} 49^{\circ} \mathrm{C}$ heat stimulus (Fig. 2). Based on their quickly adapting response to heat, 22 units were characterized as QC units. In contrast, 21 units had slowly adapting, sustained responses to heat and were classified as SC units (Fig. 2 B). Distributions of the heat thresholds in QC fibers and SC fibers were almost nonoverlapping (Fig. 2C), but such clear separation was not apparent for mechanical thresholds. However, QC fibers had significantly lower thresholds than SC fibers to both heat and mechanical stimuli (Table 1). QC fibers also tended to have a larger response to the $49^{\circ} \mathrm{C}, 3 \mathrm{~s}$ heat stimulus.

\section{CMHs respond to cowhage}

All 43 CMHs were tested with both inactive and active cowhage. Figure 3 shows a typical cowhage response. The response during the $15 \mathrm{~s}$ cowhage application interval (shaded area in figure) was caused by the mechanical activation elicited by spicule insertion and did not differ between inactive versus active cowhage application ( $31 \pm 3$ vs $32 \pm 3$ APs, respectively, $n=43$ ). Minimal activity occurred after completion of the application of heatinactivated cowhage spicules (Fig. 3A).

Active cowhage elicited a delayed, but vigorous response (121 $\mathrm{AP} / 5 \mathrm{~min}$ ) (Fig. 3B). The afferent discharged with high-
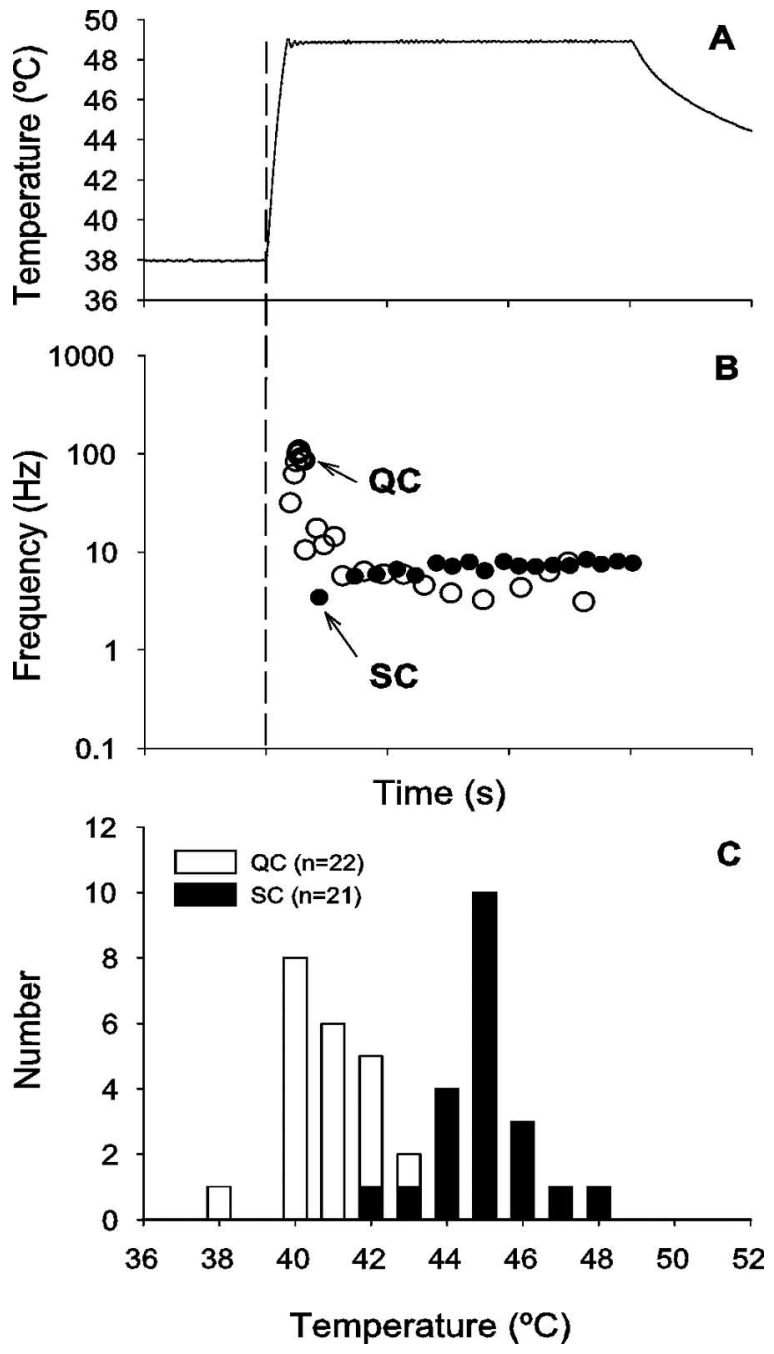

Figure 2. Two types of heat responses are observed in heat-sensitive C-fibers. $\boldsymbol{A}$, Stimulus waveform of the laser heat stimulus $\left(49^{\circ} \mathrm{C}, 3 \mathrm{~s}\right)$ used to differentiate responses to heat. $\boldsymbol{B}$, The QC fiber (open circles) exhibits a high-frequency neuronal discharge at stimulus onset, but this response adapts within $<1 \mathrm{~s}$. In contrast, the $\mathrm{SC}$ fiber (filled circles) shows an almost constant discharge over the stimulation period. In $\boldsymbol{B}$, each dot corresponds to time of occurrence of an action potential. Instantaneous frequency is computed based on the reciprocal of the interval after the action potential. $\boldsymbol{C}$, Histogram for the heat thresholds in QC and SC fibers shows two almost nonoverlapping distributions. Heat thresholds were determined with a staircase heat stimulus from $38^{\circ} \mathrm{C}$ to $49^{\circ} \mathrm{C}$ with an increment of $1^{\circ} \mathrm{C}$ per $1 \mathrm{~s}$.

frequency bursts followed by $\sim 10 \mathrm{~s}$ long intervals of no activity. An instantaneous frequency histogram for this fiber (Fig. 3C) revealed two peaks, the peak at $0.1 \mathrm{~Hz}$ reflects the $10 \mathrm{~s}$ interburst intervals, and the peak at $3 \mathrm{~Hz}$ corresponds to the most often observed intraburst frequency. Interestingly, in response to the $49^{\circ} \mathrm{C}$ noxious heat stimulus, the same afferent showed a relatively constant discharge at $\sim 10 \mathrm{~Hz}$ (Fig. 3D), and was classified as an SC fiber.

\section{A single cowhage spicule can vigorously activate CMHs}

In five units, we attempted to elicit a response from insertion of a single active cowhage spicule in a mechanosensitive spot in the receptive field. Of 12 single spicule trials in these five units (at least two trials/unit), a response was elicited in only four trials (in three different units). Two responses to the single spicule were quite large and were remarkably similar to those generated by the multispicule insertion (Fig. 4). In one fiber, labeled as AC46.3C, 
Table 1. Comparison of physiological parameters between $\mathrm{QC}$ and SC fibers and their responses to pruritic stimuli (cowhage and histamine)

\begin{tabular}{lcc}
\hline & $\mathrm{CMH}(n=43)$ & \\
\cline { 2 - 3 } & $\mathrm{QC}(n=22)$ & $\mathrm{SC}(n=21)$ \\
\hline Conduction velocity & $0.81 \pm 0.04$ & $0.85 \pm 0.02$ \\
Mechanical threshold & $1.5 \pm 0.1$ & $2.2 \pm 0.17^{* *}$ \\
Heat threshold $\left({ }^{\circ} \mathrm{C}\right)$ & $40.9 \pm 0.25$ & $45.0 \pm 0.28^{* * *}$ \\
Response to $3 \mathrm{~s}, 49^{\circ} \mathrm{C}(\mathrm{APs})$ & $26.3 \pm 1.6$ & $22.5 \pm 3.3(n=16)$ \\
Response to cold bar (APs) & $11.5 \pm 1.4$ & $7.1 \pm 2.7$ \\
Cowhage & & \\
$\quad$ Total response (APs/ $/ 5$ min) & $97.1 \pm 13.7(n=19)$ & $49.0 \pm 8.3^{* *}(n=20)$ \\
$\quad$ Number of bursts & $9.4 \pm 1.8(n=19)$ & $7.2 \pm 1.2(n=20)$ \\
$\quad$ Average intraburst frequency $\left(1 / t_{2}\right)(\mathrm{Hz})$ & $6.6 \pm 2.5(n=19)$ & $1.3 \pm 0.18^{*}(n=20)$ \\
$\quad$ Average interburst interval $\left(t_{1}\right)(s)$ & $9.3 \pm 1.3(n=19)$ & $15.3 \pm 1.8^{*}(n=20)$ \\
Histamine & & $39.3 \pm 5.4(n=16)$ \\
$\quad$ Total response (APs/5 min) & $29.8 \pm 3.3(n=13)$ & $7.8 \pm 1.2(n=16)$ \\
$\quad$ Number of bursts & $5.9 \pm 1.3(n=13)$ & $1.5 \pm 0.37(n=16)$ \\
$\quad$ Average intraburst frequency $\left(1 / t_{2}\right)(\mathrm{Hz})$ & $8.5 \pm 3.5(n=13)$ & $18.3 \pm 2.0(n=16)$ \\
$\quad$ Average interburst interval $\left(t_{1}\right)(s)$ & $15.6 \pm 2.2(n=13)$ & $(\mathrm{s})$ \\
\hline
\end{tabular}

QC fibers had significantly smaller mechanical and heat thresholds, and the responses to cowhage were significantly larger, with a significantly higher intraburst frequency and a significantly smaller interburst interval. Histamine responses did not differ between $Q \mathrm{C}$ and $\mathrm{SC}$ fibers.

${ }^{*} p<0.01$, Mann-Whitney U test (QC vS SC); ${ }^{* *} p<0.01$, unpaired $t$ test (QC vs SC); ${ }^{* * *} p<0.001$, unpaired $t$ test (QC vs SC).

quency histogram (similar to Fig. 3C) for all trials in cowhage responsive units. We then averaged across all trials to obtain the averaged histogram of instantaneous frequency shown in Figure $6 D$. This histogram has three apparent peaks: the peak at $\sim 0.1 \mathrm{~Hz}$ corresponds to the average interburst interval (of around $10 \mathrm{~s}$ ), the peak at $\sim 1 \mathrm{~Hz}$ reflects the average intraburst frequency, and the peak at $40 \mathrm{~Hz}$ corresponds to the high intraburst discharge seen in three QC fibers.

\section{QC fibers respond more vigorously to cowhage than SC fibers}

Of the 39 cowhage responders, 21 were classified as SC type units, whereas 18 were QC type units. The time course of the cowhage induced neuronal excitation was similar in both populations (Fig. 7A). The highest activity occurred 50-60 s after administration of cowhage, and the dis-

the response to 18 spicules (83 APs) (Fig. $4 A$ ) was less than the activity induced by a single spicule (97 APs) (Fig. 4B). A mechanical response during spicule insertion was elicited in all trials for which a response to cowhage was obtained and also in seven of eight trials with no cowhage response. Therefore, the occurrence of a mechanical response during spicule insertion did not predict the response to a single spicule.

\section{Responses and response patterns to cowhage are variable}

The total response to active cowhage could be quite variable across trials for a given fiber (Fig. 5). This variability was observed in most fibers that were tested multiple times with active cowhage. Of 33 fibers that were tested two to three times with cowhage, 21 fibers had at least one cowhage trial that would be classified as a "no-response" trial ( $<10 \mathrm{APs} / 5 \mathrm{~min}$ ), and three units were nonresponders throughout multiple trials. "No response" does not appear to be the result of tachyphylaxis or desensitization of the cowhage response because no-response trials occurred with an equal frequency between trials 1, 2, and 3 across fibers. Furthermore, the average response did not differ between the three trials (Fig. 5).

Variability in the magnitude of the maximal cowhage response was also observed across fibers. Of the $43 \mathrm{CMHs}$ tested, 39 were classified as cowhage responders. Cowhage responders had a mean response to inactive cowhage of $5.7 \pm 1.1 \mathrm{APs} / 5 \mathrm{~min}$, whereas the average response to active cowhage spicules was $72.5 \pm 8.7 \mathrm{APs} / 5 \mathrm{~min}$.

Examples of the three different discharge patterns that were observed are shown in Figure 6 (see also Fig. 3, 4). Approximately two-thirds of the fibers exhibited a bursting response where the discharge frequencies during the burst were around $0.5-5 \mathrm{~Hz}$ and the quiet interval between bursts was around $10 \mathrm{~s}$ (Figs. 3, 4, 6A). Three fibers (all QC fibers) exhibited very high instantaneous frequencies during the burst (Fig. 6B, note different scale). For approximately one-third of the fibers, the bursting was not as obvious and the discharge pattern was relatively irregular (Fig. $6 C$ ). In a given fiber, bursting could be observed in response to one application of cowhage, and an irregular discharge in response to another.

To obtain a first estimate of the population response pattern in C-fibers to cowhage, we generated the instantaneous fre- charge declined linearly with time thereafter. However, the total discharge in QC fibers was greater than in SC fibers $(97.1 \pm 13.7$ vs $49.0 \pm 8.3 \mathrm{APs} / 5 \mathrm{~min}$, respectively; $p<0.01, t$ test) (Table 1 ).

We wished to determine whether the bursting discharge pattern in response to cowhage differed between the SC and QC populations. A defining feature for the onset of a burst is the occurrence of a long interspike interval followed by a short interspike interval. As shown in Figure $7 B$, we computed the ratio of $t_{1} / t_{2}$ for all action potentials in the response and defined the onset of a burst as the time when $t_{1} / t_{2}>5$. For the trial with the maximum response, we then determined the number of bursts during the 5 min after application, the average interval between bursts $\left(t_{1}\right)$, and the average instantaneous frequency of the first two action potentials in the bursts $\left(1 / t_{2}\right)$. The number of bursts during the response to cowhage was not significantly different between QC and SC fibers (Table 1). In contrast, the interval between bursts $\left(t_{1}\right)$ was significantly smaller in QC fibers than SC fibers, and the peak frequency $\left(1 / t_{2}\right)$ in QC fibers was significantly higher than in SC fibers (Fig. 7C, Table 1). A plot of the average intraburst frequencies reveals that there were $3 \mathrm{QC}$ units with considerably higher intraburst peak discharge frequencies (Fig. 7C). When these three fibers are excluded from the analysis, the QC fibers still have significantly higher intraburst frequencies than the SC fibers $(2.1 \pm 0.3 \mathrm{~Hz}$ vs $1.3 \pm .0 .2 \mathrm{~Hz} ; p<0.02, t$ test $)$.

\section{CMHs respond to histamine}

The responses of a typical CMH to saline and histamine $(1 \mu \mathrm{g})$ are shown in Figure 8 (same fiber as in Fig. 3). The needle insertion and injection of the $10 \mu \mathrm{l}$ volume into the receptive field produced a response during both the saline and histamine trials, presumably because of the mechanical stimulation of the afferent. In contrast to the injection of saline, however, histamine caused lasting excitation. Notably, histamine led to a bursting discharge that was similar to that seen for cowhage.

Similar to the activity caused by cowhage, different discharge patterns were observed after the histamine injection. About half of the units showed a high-frequency bursting discharge, whereas the remainder showed an irregular discharge with intermittent bursts. Seven units that were responsive to cowhage were completely unresponsive to histamine and were excited only during needle insertion and injection. 

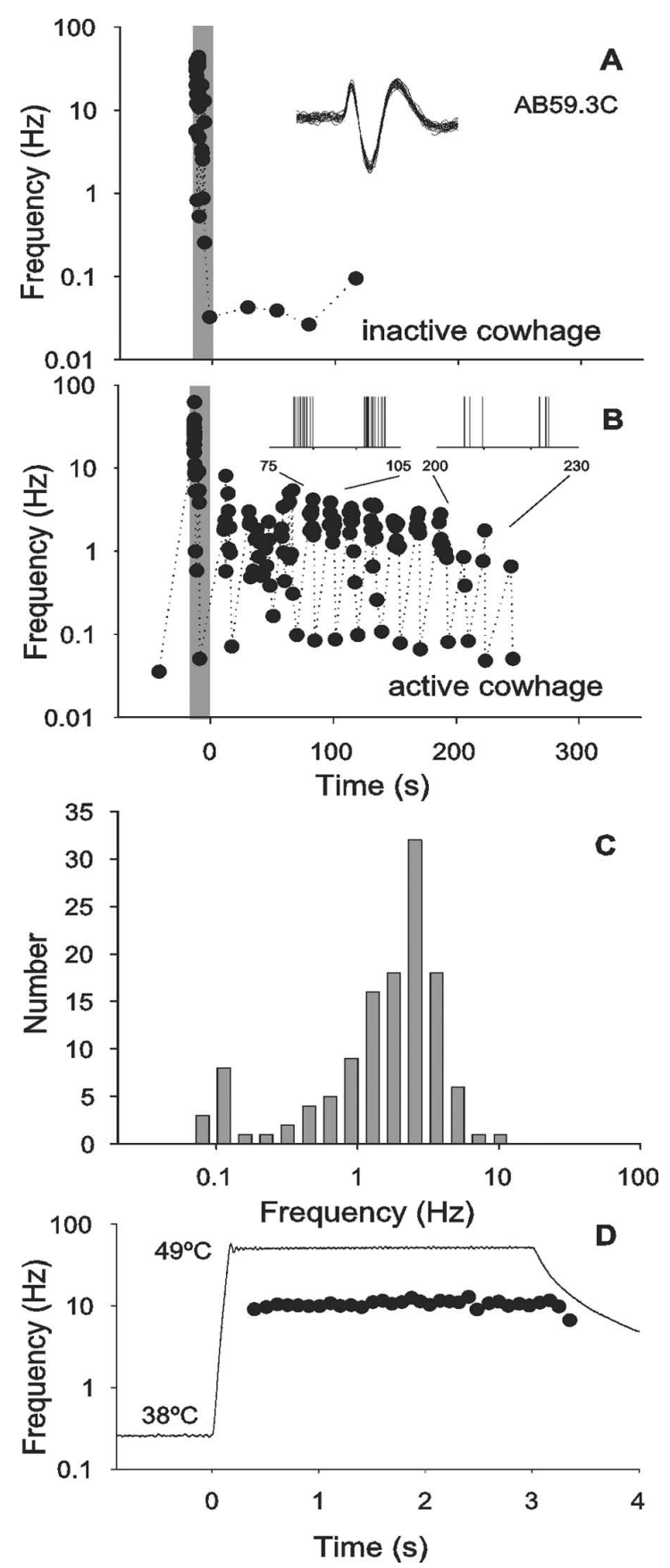

Figure 3. Active cowhage causes bursting discharge in $\mathrm{CMH}$ afferent. $A$, Response induced by inactive cowhage ( 4 spicules) in unit AB59.3C. Inset, Superimposed action potential waveforms $(n=10)$. $\boldsymbol{B}$, Response of the same afferent to active cowhage ( 8 spicules). Instantaneous action potential frequency is plotted as function of time after stimulus application. Each black dot indicates the occurrence of an action potential. The gray bar indicates the time of application of the spicules to the receptive field. A large mechanical response was typically observed during the cowhage application period. Inset, Expanded time course of response over two different intervals (vertical line corresponds to time of action potential). C, Histogram of the interspike frequencies for the response to active cowhage shown in $\boldsymbol{B}$. Two peaks are apparent. Note that bins are in $\log$ increments (factors of $\sqrt{2}$ ). $\boldsymbol{D}$, Response of the same unit to the heat stimulus $\left(49^{\circ} \mathrm{C}, 3 \mathrm{~s}\right)$. Although this unit showed a bursting discharge to cowhage, the response to heat was slowly adapting and the unit was classified as an SC fiber.

Histamine was tested in $38 \mathrm{CMHs}$, and $76 \%$ (29 of 38) were classified as responders. All of these 29 histamine-responsive units were also responsive to cowhage. Of the nine remaining units tested with histamine and found to be nonresponsive, seven responded only to cowhage, and two units had no response to cowhage or histamine. Unlike cowhage, the bursting discharge patterns in response to histamine were similar for the QC and SC fibers; the number of bursts, the interburst interval $\left(t_{1}\right)$, and the intraburst frequency $\left(1 / t_{2}\right)$ were not significantly different (Table 1 ).

The response of CMHs to cowhage is larger than to histamine The responses of units classified as responders were used to construct time-course plots for the activity evoked by histamine and cowhage (Fig. 9A). The time courses of the cowhage and histamine responses were similar. The peak discharge occurred within the first $60 \mathrm{~s}$, and the response decayed substantially in the first 5 min. Importantly, time courses of the responses to 1 or $10 \mu \mathrm{g}$ of histamine were similar. For the 38 fibers tested with both cowhage and histamine, there was no correlation between the magnitudes of the cowhage response and the histamine response (Fig. $9 B)$, suggesting that different activation mechanisms are involved. The total response to cowhage was significantly larger than the response to histamine $(67 \pm 8.4$ vs $27.4 \pm 3.4 \mathrm{APs} / 5 \mathrm{~min}$; ANOVA followed by Bonferroni test, $p<0.001$ ) (Fig. 9C).

\section{Capsaicin does not cause lasting excitation in the majority of CMH afferents}

Although most CMH units responded during the injection of 10 $\mu \mathrm{g}$ capsaicin, this response was not substantially greater than the response to vehicle injection, and the units did not show activity beyond the injection period. Therefore, most $\mathrm{CMH}$ units were classified as nonresponders. Only three units showed lasting responses to capsaicin, and these units were also classified as cowhage and histamine responders. The one fiber that responded robustly to capsaicin ( $80 \mathrm{APs} / 5 \mathrm{~min}$ ) had smaller responses to histamine and cowhage ( 31 and $15 \mathrm{APs} / 5 \mathrm{~min}$, respectively). The other two capsaicin-responsive units just met our criteria, having exactly $10 \mathrm{APs} / 5 \mathrm{~min}$. In these two units, the histamine response was at least two times greater than the capsaicin response, and the cowhage response was at least two times greater than the histamine response. Although most $\mathrm{CMHs}$ did not exhibit a prolonged response to capsaicin and were classified as nonresponders, capsaicin had an effect on them, because most CMHs (17 of 28 tested) were desensitized to subsequent mechanical stimuli applied to the capsaicin injection site.

Of the $34 \mathrm{CMHs}$ that were tested with all three compounds, 32 responded to cowhage, 27 responded to histamine, and only 3 units with lasting activation after capsaicin fulfilled the criteria of responders. The majority of the units (27) responded to both histamine and cowhage. Two CMHs did not respond to any of the chemical stimuli presented.

\section{Mechanically insensitive afferent fibers}

Five CMi afferents were tested with cowhage and none responded. In contrast, a large histamine and capsaicin response was observed in one $\mathrm{CMi}$, and two CMi afferents responded only to capsaicin. Finally, two CMi fibers did not respond to any of the stimuli presented.

\section{Discussion}

We used cowhage spicules to investigate neuronal mechanisms of nonhistaminergic itch. Application of cowhage and histamine, but not their controls, produced scratching behavior in nonhuman primates. Furthermore, the monkeys did not scratch in response to the intradermal injection of capsaicin or its vehicle. 


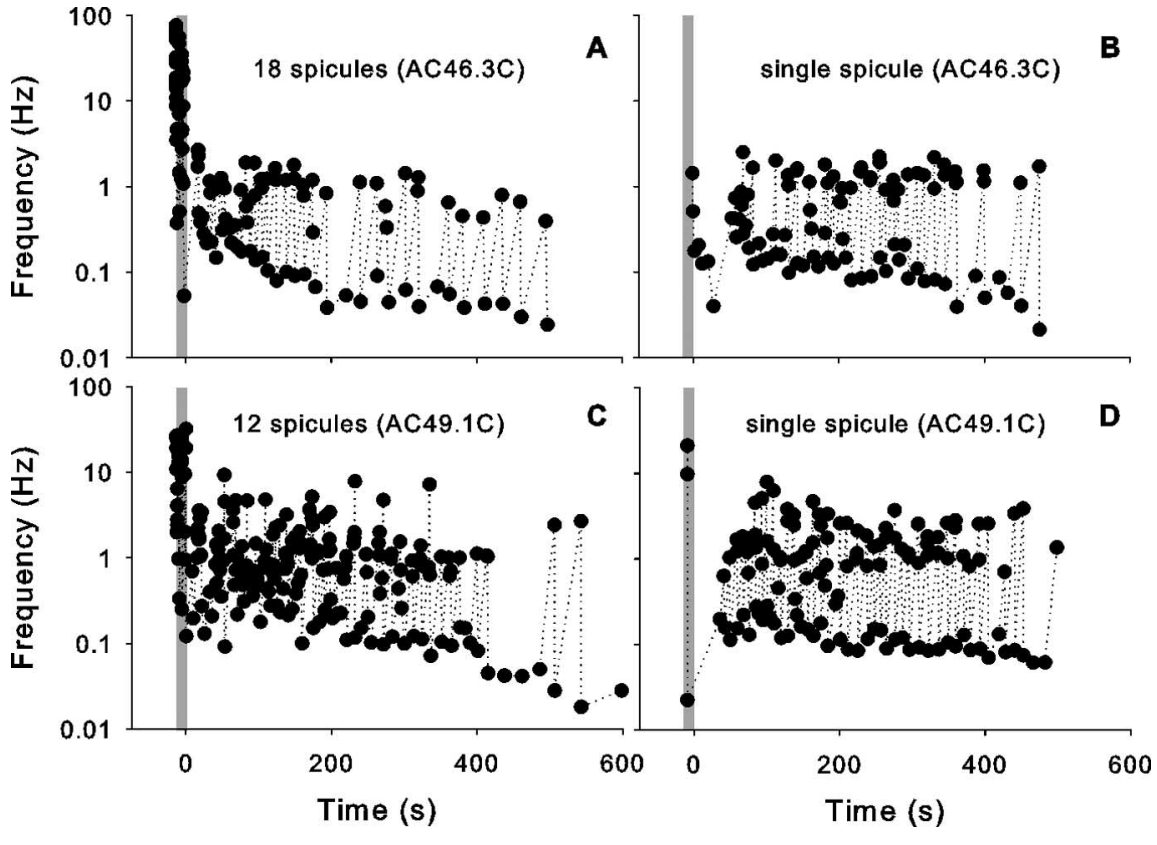

Figure 4. The response to a single cowhage spicule can be quite vigorous. $A, C$, Response elicited after insertion of multiple active cowhage spicules into the receptive field of two different units (AC46.3C, $A C 49.1 C) . \boldsymbol{B}, \boldsymbol{D}$, The activity elicited after insertion of a single cowhage spicule can be comparable with that evoked by multiple spicules. The format similar to that used in Figure $3 B$. Note that the mechanically-evoked response during the application period (gray bar) is much less when a single spicule is inserted.

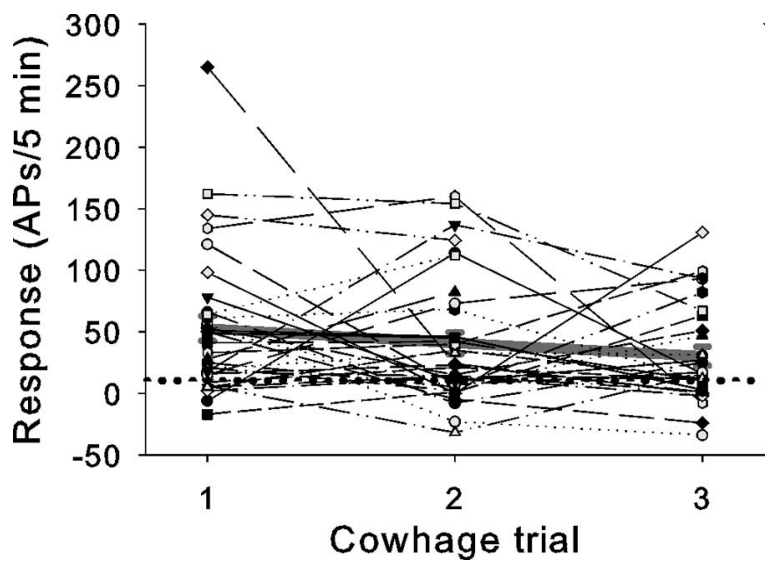

Figure 5. Responses to cowhage varied within fibers. For each fiber tested with multiple applications of cowhage, the number of action potentials in each 5 min trial was plotted. Responses were corrected for ongoing spontaneous activity observed during the baseline period before the application of cowhage. This explains negative responses. The average response for each trial is plotted in gray. Trials resulting in $\geq 10$ action potentials were regarded as a positive responses (dotted line) if the number of action potentials was at least twice as large as the number observed after administration of inactive spicules.

These results demonstrate that cowhage and histamine are pruritogenic stimuli in the monkey.

A labeled afferent line for the sensation of itch has been proposed based on the discovery of histamine-sensitive CMi afferents in humans (Schmelz et al., 1997) and histamine-selective spinothalamic dorsal horn neurons in cats (Andrew and Craig, 2001). In rats, dorsal horn neurons are activated by both pruritic and algogenic agents (Carstens, 1997; Jinks and Carstens, 2000). In monkeys, polymodal spinothalamic dorsal horn cells respond either to cowhage or histamine but not both (Davidson et al., 2007).

However, in recent microneurography experiments in hu- mans, none of the $17 \mathrm{CMi}$ afferents responded to cowhage (Namer et al, 2008). Similarly, in the present study, none of the five CMi fibers responded to cowhage spicules. Therefore, CMi afferents are unlikely to mediate the sensation of cowhageinduced itch, and other primary afferent fibers must exist that can mediate itch sensation.

CMHs are activated by cowhage spicules and histamine but not capsaicin The majority (39 of 43) of CMHs responded to the application of cowhage spicules. A similar percentage of CMHs responding to cowhage was also found in human microneurography experiments (Namer et al., 2008). These results are in agreement with a previous study in cats (Tuckett and Wei, 1987b) in which 84\% of CMHs responded to cowhage. Thus, afferent neurons typically described as C-fiber polymodal nociceptors respond to cowhage.

The majority ( 29 of $38,76 \%$ ) of CMHs in monkey were also excited by intradermal injection of histamine. Histamine responses were significantly smaller than those induced by cowhage spicules (Fig. 9C), but the time course of excitation was similar (Fig. 9A). In human microneurography experiments, the incidence of $\mathrm{CMHs}$ that responded to histamine iontophoresis was slightly lower (47-66\%), but the magnitude of the response was very weak (Handwerker et al., 1991; Schmelz et al., 1997) (Namer et al., 2008).

Two explanations other than species may account for the lower incidence and response magnitude to histamine in the human microneurograpy studies. First, the application methods differed between the studies (intradermal injection vs iontophoresis). Skin appendages (e.g., hair follicles and sweat glands) are thought to be a major pathway for iontophoretically delivered drugs (Magerl et al., 1990; Kanikkannan, 2002). Furthermore, pricking histamine into the skin produced a larger itch sensation but a smaller flare than histamine iontophoresis (Darsow et al., 1996), leading these authors to hypothesize that iontophoresis may bypass histamine-sensitive superficial nerve endings. The 10 $\mu \mathrm{l}$ volume of the intradermal injections easily diffuses to the epidermal fibers. Second, the marking technique used in microneurography relies on ongoing electrical stimulation at the skin. Recent electrophysiological experiments in pigs suggest that this stimulation decreases the excitability of the C-fibers to heat stimuli (O. Obreja, M. Schmelz, and M. Ringkamp, unpublished observation). Similarly, afferent responses to heat are diminished after antidromic nerve stimulation (Peng et al., 2003). Repetitive electrical stimulation may particularly diminish weak neuronal responses (e.g., histamine responses in $\mathrm{CMHs}$ ), whereas large responses (e.g., cowhage responses in CMHs) are less affected.

Most CMHs did not exhibit a prolonged response to the capsaicin injection and were classified as nonresponders. Similarly, $\mathrm{CMHs}$ in human and monkey respond weakly to capsaicin (Baumann et al., 1991; LaMotte et al., 1992; Schmelz et al., 2000). These findings are consistent with recent observations in mice suggesting that polymodal C-fibers lack transient receptor potential vanilloid receptor-1 (Lawson et al., 2008). However, the ma- 

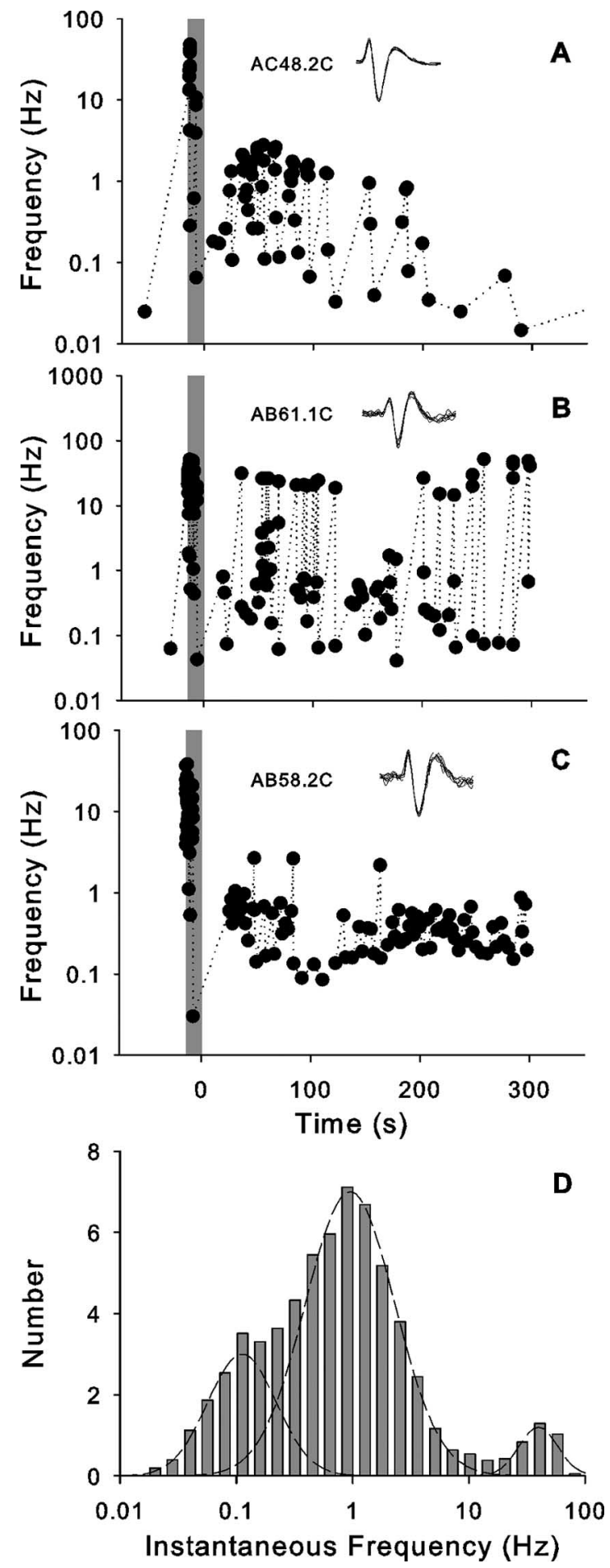

Figure 6. Three different types of discharge patterns were seen in response to active cowhage. $\boldsymbol{A}$, Bursting discharge at intermediate frequency in unit AC48.2C. $\boldsymbol{B}$, High-frequency bursting discharge in unit $A B 61.1 C$. Note that the scale is changed. $C$, Slow irregular discharge with intermittent bursts in unit $A B 58.2 C$. Gray areas mark time period of cowhage application. The format similar to that used in Figure $3 B$. D, Instantaneous frequency histogram averaged across all cowhage trials from cowhage responsive afferents. Three peaks are apparent. The format is similar to that used in Figure $3 C$.

jority of CMHs in the present study (as well as in previous studies in monkeys and humans) (Baumann et al., 1991; LaMotte et al., 1992; Schmelz et al., 2000) were desensitized to natural stimuli after the capsaicin injection indicating that capsaicin did have an
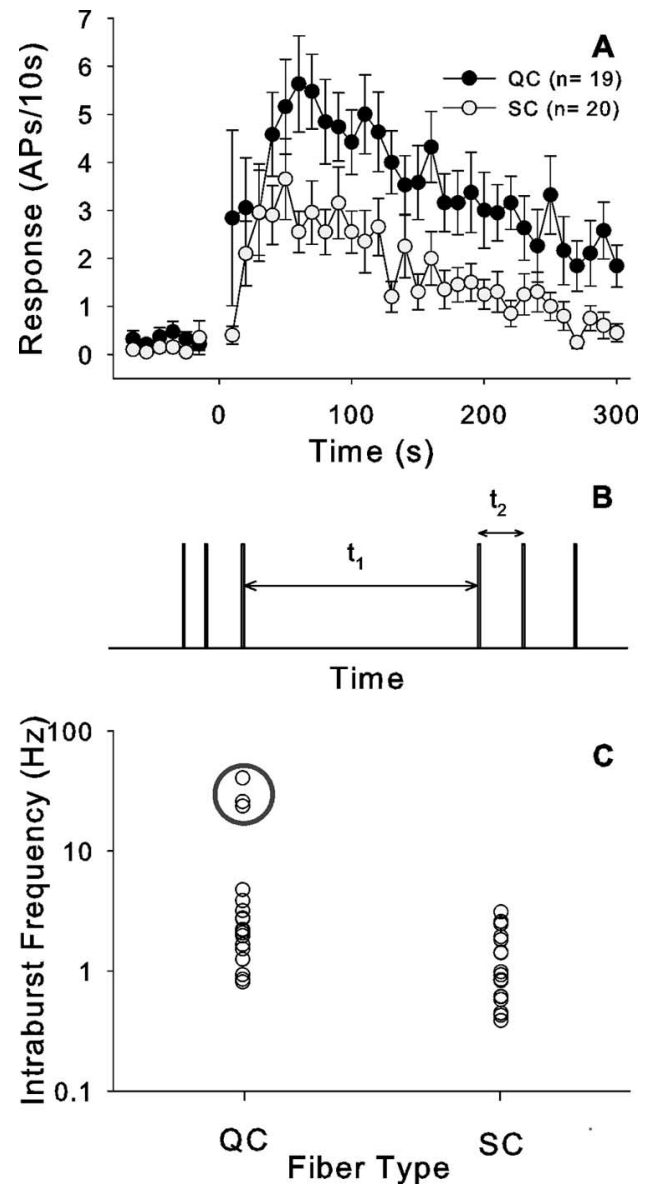

Figure 7. $Q C$ and SC fibers respond differently to cowhage application. $A$, Time course of cowhage-induced excitation in $Q C$ and $S C$ fibers looks similar, but the discharge in $Q C$ fibers is larger (bin size, $10 \mathrm{~s}$ ). $\boldsymbol{B}$, Parameters extracted from the discharge pattern to define a burst: $t_{1}$, interburst interval, $t_{2}$, intraburst interval. The onset of a burst was defined by $t_{1} / t_{2} \geq 5$. $C$, Intraburst frequency $\left(1 / t_{2}\right)$ in $Q C$ and SC fibers. Each circle corresponds to a different fiber. The average intraburst frequency for that fiber is plotted. QC fibers had significantly higher intraburst frequencies than $\mathrm{SC}$ fibers. Three QC fibers had particularly high intraburst frequencies (enclosed by gray circle). Error bars indicate SEM.

effect. Desensitization of CMHs may explain the complete loss of cowhage-induced itch in human after topical capsaicin treatment (Johanek et al., 2007).

\section{Variability of cowhage responses}

Cowhage responses were variable in a given fiber. Some applications failed to induce any activity, whereas others induced clear responses, suggesting that cowhage spicules need to be inserted close to the terminal ending of the afferent to cause excitation. The response variability is likely caused by the variations in the cowhage stimulus, because our standard application method did not allow the number or location of the inserted spicules to be precisely controlled. However, when single spicules were inserted under microscopic visualization at a mechanically sensitive spot in the receptive field, the evoked activity was generally similar to that produced by multiple spicules.

\section{Distinct subgroups of CMHs differ in their} cowhage responses

CMHs were classified as quickly or slowly adapting fibers based on their response to a short duration heat stimulus. Consistent with our previous findings (Meyer and Campbell, 1981), QC 

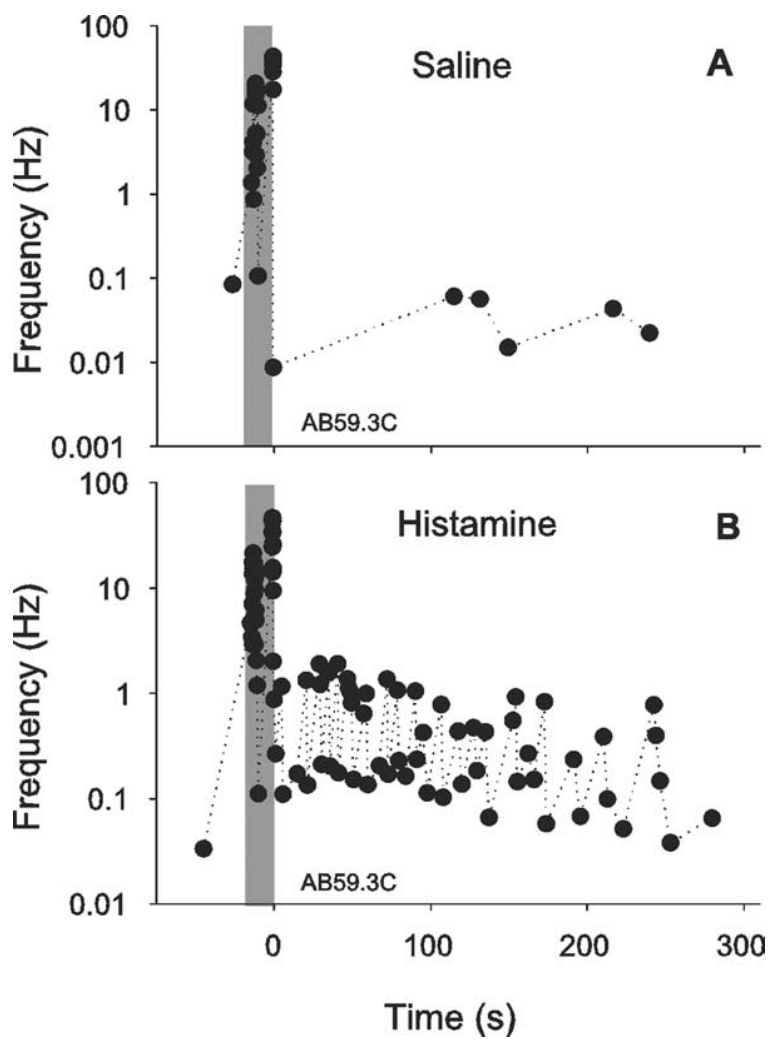

Figure 8. CMH response to histamine. $A$, The fiber (AB59.3C) responded to insertion of the needle and injection of the volume of saline ( $10 \mu \mathrm{l})$, but responded only weakly (5 APs) during the $5 \mathrm{~min}$ after the injection. $\boldsymbol{B}$, Histamine injection $(1 \mu \mathrm{g})$ produced a long-lasting bursting discharge (same fiber as in Fig. 3). The format is similar to that used in Figure 3B. Gray areas mark the time period of needle insertion and injection.

fibers also had lower mechanical and heat thresholds than SC fibers. It is possible that the receptive endings of $\mathrm{QC}$ fibers terminate closer to the surface of the epidermis, whereas SC fibers lie deeper within the skin. Consistent with this hypothesis, QC fibers had significantly larger responses to the superficially applied cowhage spicules than SC fibers. QC fibers may correspond to recently described nerve fibers expressing Mas-related G-proteincoupled receptor $\mathrm{D}$, which, in mouse, exclusively terminate in the superficial layers of the epidermis (Zylka et al., 2005).

Molecular mechanisms of cowhage-induced itch

The mechanism by which cowhage activates neurons is unknown. It is likely of chemical origin, because heat-inactivated spicules do not produce itch and do not activate CMHs. In humans, topical antihistamine treatment does not block cowhageinduced itch (Johanek et al., 2007). Shelley and Aurthur $(1955 a, b)$ identified a proteinase they called mucunain as the pruritogen in cowhage spicules. Mucunain has recently been reisolated from cowhage and identified as a novel cysteine protease that activates proteinase-activated receptor 2 (PAR2) and PAR4 (Reddy et al., 2008). PAR2 has been implicated previously in itch sensation (Steinhoff et al., 2003).

\section{Bursting in sensory neurons}

Bursting discharge is common in cold-fiber afferents and is likely caused by a cyclic oscillation in the membrane potential (Schäfer et al., 1986). Such oscillations have also been observed in large dorsal root ganglion neurons after peripheral nerve injury, and they are thought to be related to $I_{\mathrm{h}}$ currents (Chaplan et al., 2003;
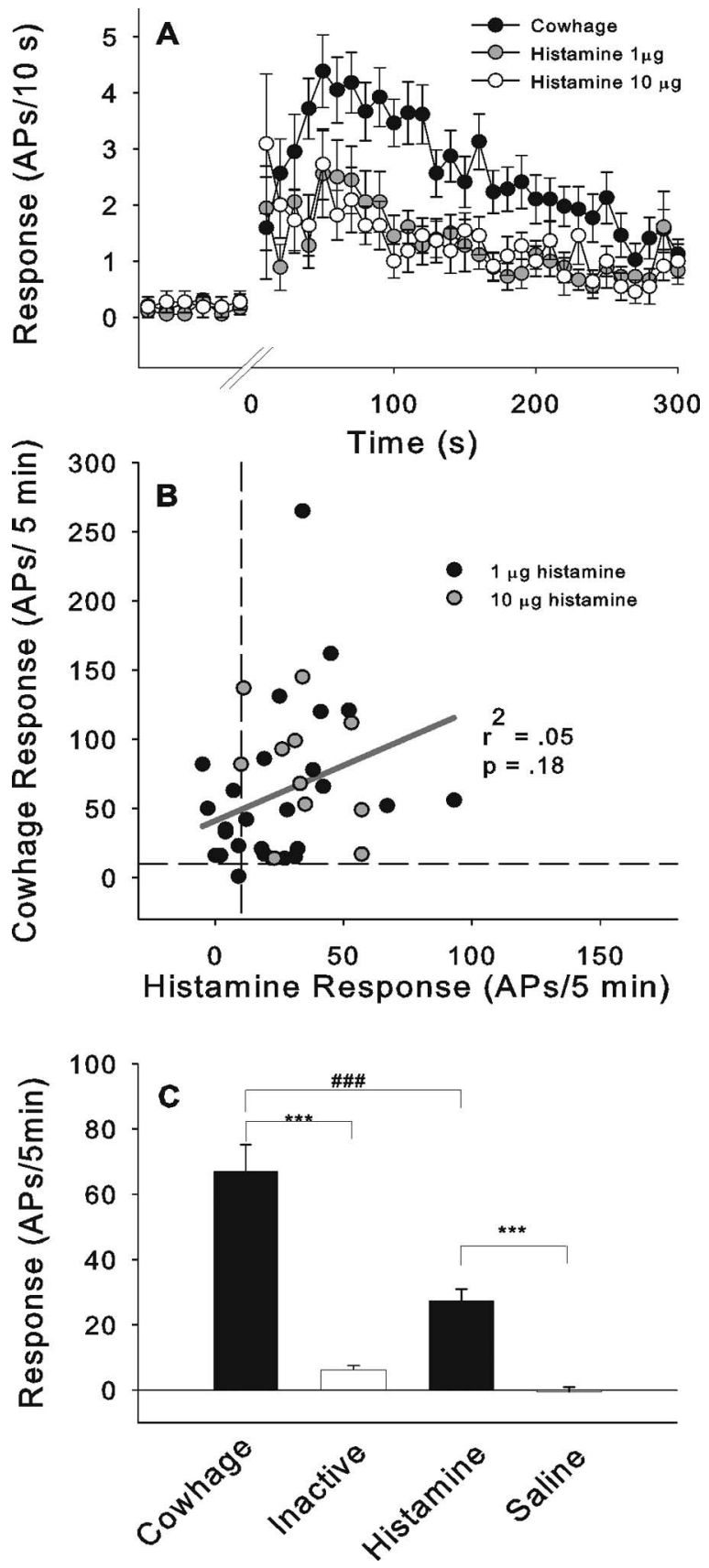

Figure 9. A, Time course of the neuronal activity after the administration of cowhage or histamine $(1 \mu \mathrm{g}, 10 \mu \mathrm{g})$. Time courses of cowhage $(n=39)$ and histamine $(1 \mu \mathrm{g}, n=18 ; 10$ $\mu g, n=11)$ excitation were similar. Time courses for high and low dose histamine were not different. $\boldsymbol{B}$, Scatter plot of the total response to cowhage and histamine. There was no correlation between responses suggesting that the excitations are induced by two independent mechanisms. C, Comparison between the total response during the $5 \mathrm{~min}$ after the application of cowhage and histamine and respective controls. Responses to cowhage were significantly larger than those to histamine (ANOVA, $F_{(41,3)}=40.6, p<0.01$; followed by Bonferroni test,

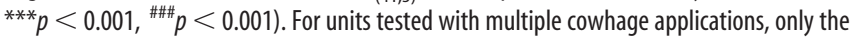
maximal response was used in the analysis. Error bars indicate SEM.

Sun et al., 2005) or to a reciprocal activation between TTXsensitive voltage-dependent sodium currents and potassium leak currents (Amir et al., 2002). Oscillations in membrane potential may account for the bursting behavior in $\mathrm{CMHs}$ after cowhage. However, a bursting behavior is not seen in CMHs in response to maintained heat stimuli suggesting that other mechanisms may be involved. 


\section{Neuronal activity in CMHs: itch or pain?}

The majority of polymodal C-fiber afferents responded to cowhage. This presents a dilemma regarding their potential role in itch, because these fibers also respond to noxious mechanical and heat stimuli and are thought to encode pain sensation. We would like to discuss three possible solutions to this dilemma.

One possibility is that a subpopulation of $\mathrm{C}$-fibers encodes cowhage itch. We found that QC fibers had a more robust cowhage response than SC fibers. Notably, 3 QC fibers exhibited very high $(\sim 40 \mathrm{~Hz})$ intraburst discharge frequencies. It may be that QC fibers (or a subset thereof) encode itch, and SC fibers encode pain. The response of QC fibers to heat and mechanical stimuli might account for the itch that can be produced by these stimuli.

Another possibility is that the firing pattern of an afferent neuron distinguishes itch from pain sensations. In a small sample of human CMHs, a specific firing pattern for puritic (histamine) and algogenic (mustard oil) substances was not found (Handwerker et al., 1991). In the present study, however, cowhage and histamine induced bursting discharge in both SC and QC fibers. In contrast, both populations show a nonbursting, adapting response when exposed to a long-lasting (30 s), extremely noxious $\left(53^{\circ} \mathrm{C}\right)$ heat stimulus (Meyer and Campbell, 1981). Previous investigators have reported that certain neuropeptides are released by primary afferents when the discharge pattern is bursting in nature (Lever et al., 2001). Bursting in unmyelinated polymodal afferents may cause the sensation of itch by releasing itch specific neurotransmitters onto dorsal horn neurons. Gastrin-releasing peptide has recently been identified as an itch specific neurotransmitter (Sun and Chen, 2007). This temporal pattern hypothesis is not consistent with the observation that the quality of electrocutaneous-induced itch does not appear to depend on the temporal pattern of stimulation (Tuckett, 1982).

A third possibility is that a different class of afferents encodes cowhage itch. Recently, an A-fiber block produced by nerve compression significantly reduced cowhage itch (Shimada et al., 2007). Interestingly, a subpopulation of $A \delta$-fibers is responsive to cowhage (Tuckett and Wei, 1987a) (R. Schepers, personal communication), but additional studies are needed to fully understand the role of these afferents in cowhage-induced itch.

\section{References}

Amir R, Liu CN, Kocsis JD, Devor M (2002) Oscillatory mechanism in primary sensory neurones. Brain 125:421-435.

Andrew D, Craig AD (2001) Spinothalamic lamina I neurons selectively sensitive to histamine: a central neural pathway for itch. Nat Neurosci 4:72-77.

Baumann TK, Simone DA, Shain CN, LaMotte RH (1991) Neurogenic hyperalgesia: the search for the primary cutaneous afferent fibers that contribute to capsaicin-induced pain and hyperalgesia. J Neurophysiol 66:212-227.

Campbell JN, Meyer RA (1983) Sensitization of unmyelinated nociceptive afferents in the monkey varies with skin type. J Neurophysiol 49:98-110.

Carstens E (1997) Responses of rat spinal dorsal horn neurons to intracutaneous microinjection of histamine, capsaicin, and other irritants. J Neurophysiol 77:2499-2514.

Chaplan SR, Guo HQ, Lee DH, Luo L, Liu C, Kuei C, Velumian AA, Butler MP, Brown SM, Dubin AE (2003) Neuronal hyperpolarizationactivated pacemaker channels drive neuropathic pain. J Neurosci 23:1169-1178.

Darsow U, Ring J, Scharein E, Bromm B (1996) Correlations between histamine-induced wheal, flare and itch. Arch Dermatol Res 288:436-441.

Davidson S, Zhang X, Yoon CH, Khasabov SG, Simone DA, Giesler GJ Jr (2007) The itch-producing agents histamine and cowhage activate sepa- rate populations of primate spinothalamic tract neurons. J Neurosci 27:10007-10014.

Handwerker HO, Forster C, Kirchhoff C (1991) Discharge patterns of human C-fibers induced by itching and burning stimuli. J Neurophysiol 66:307-315.

Ikoma A, Handwerker H, Miyachi Y, Schmelz M (2005) Electrically evoked itch in humans. Pain 113:148-154.

Jinks SL, Carstens E (2000) Superficial dorsal horn neurons identified by intracutaneous histamine: chemonociceptive responses and modulation by morphine. J Neurophysiol 84:616-627.

Johanek LM, Meyer RA, Hartke T, Hobelmann JG, Maine DN, LaMotte RH, Ringkamp M (2007) Psychophysical and physiological evidence for parallel afferent pathways mediating the sensation of itch. J Neurosci 27:7490-7497.

Kanikkannan N (2002) Iontophoresis-based transdermal delivery systems. BioDrugs 16:339-347.

LaMotte RH, Campbell JN (1978) Comparison of responses of warm and nociceptive C-fiber afferents in monkey with human judgements of thermal pain. J Neurophysiol 41:509-528.

LaMotte RH, Lundberg LE, Torebjörk HE (1992) Pain, hyperalgesia and activity in nociceptive $\mathrm{C}$ units in humans after intradermal injection of capsaicin. J Physiol 448:749-764.

LaMotte RH, Shain CN, Simone DA, Tsai EF (1991) Neurogenic hyperalgesia: psychophysical studies of underlying mechanisms. J Neurophysiol 66:190-211.

Lawson JJ, McIlwrath SL, Woodbury CJ, Davis BM, Koerber HR (2008) TRPV1 unlike TRPV2 is restricted to a subset of mechanically insensitive cutaneous nociceptors responding to heat. J Pain 9:298-308.

Lever IJ, Bradbury EJ, Cunningham JR, Adelson DW, Jones MG, McMahon SB, Marvizón JC, Malcangio M (2001) Brain-derived neurotrophic factor is released in the dorsal horn by distinctive patterns of afferent fiber stimulation. J Neurosci 21:4469-4477.

Magerl W, Westerman RA, Möhner B, Handwerker HO (1990) Properties of transdermal histamine iontophoresis: Differential effects of season, gender, and body region. J Invest Dermatol 94:347-352.

Masood K, Green BG, LaMotte RH (2005) Psychophysical measurements of pruritic and nociceptive sensations and dysesthetic states evoked by cutaneous application of cowhage spicules in human. Soc Neurosci Abstr 31:50.9.

Meyer RA, Campbell JN (1981) Evidence for two distinct classes of unmyelinated nociceptive afferents in monkey. Brain Res 224:149-152.

Meyer RA, Walker RE, Mountcastle VB Jr (1976) A laser stimulator for the study of cutaneous thermal pain sensation. IEEE Trans Biomed Eng 23:54-60.

Meyer RA, Davis KD, Cohen RH, Treede RD, Campbell JN (1991) Mechanically insensitive afferents (MIAs) in cutaneous nerves of monkey. Brain Res 561:252-261.

Namer B, Carr R, Johanek LM, Schmelz M, Handwerker HO, Ringkamp M (2008) Separate peripheral pathways for pruritus in man. J Neurophysiol, in press.

Peng YB, Ringkamp M, Campbell JN, Meyer RA (1999) Electrophysiological assessment of the cutaneous arborization of A $\delta$-fiber nociceptors. J Neurophysiol 82:1164-1177.

Peng YB, Ringkamp M, Meyer RA, Campbell JN (2003) Fatigue and paradoxical enhancement of heat response in C-fiber nociceptors from crossmodal excitation. J Neurosci 23:4766-4774.

Reddy VB, Iuga AO, Shimada SG, LaMotte RH, Lerner EA (2008) Cowhageevoked itch is mediated by a novel cysteine protease: a ligand of proteaseactivated receptors. J Neurosci 28:4331-4335.

Schäfer K, Braun HA, Isenberg C (1986) Effect of menthol on cold receptor activity. J Gen Physiol 88:757-776.

Schmelz M, Schmidt R, Bickel A, Handwerker HO, Torebjörk HE (1997) Specific C-receptors for itch in human skin. J Neurosci 17:80038008.

Schmelz M, Schmid R, Handwerker HO, Torebjork HE (2000) Encoding of burning pain from capsaicin-treated human skin in two categories of unmyelinated nerve fibres. Brain 123:560-571.

Schmelz M, Schmidt R, Weidner C, Hilliges M, Torebjork HE, Handwerker HO (2003) Chemical response pattern of different classes of C-nociceptors to pruritogens and algogens. J Neurophysiol 89:2441-2448. 
Shelley WB, Arthur RP (1955a) Mucunain, the active pruritogenic proteinase of cowhage. Science 122:469-470.

Shelley WB, Arthur RP (1955b) Studies on cowhage (Mucuna pruriens) and its pruritogenic proteinase, mucunain. Arch Dermatol 72:399-406.

Shelley WB, Arthur RP (1957) The neurohistology and neurophysiology of the itch sensation in man. Arch Dermatol 76:296-323.

Shimada SG, Green BG, LaMotte RH (2007) Effects of a conduction block in myelinated nerve fibers on pruritic and nociceptive sensations evoked by application of cowhage spicules in human. Soc Neurosci Abstr 33:70.12.

Simone DA, Ngeow JY, Whitehouse J, Becerra-Cabal L, Putterman GJ, LaMotte RH (1987) The magnitude and duration of itch produced by intracutaneous injections of histamine. Somatosens Res 5:81-92.

Slugg RM, Meyer RA, Campbell JN (2000) Response of cutaneous A- and C-fiber nociceptors in the monkey to controlled-force stimuli. J Neurophysiol 83:2179-2191.

Steinhoff M, Neisius U, Ikoma A, Fartasch M, Heyer G, Skov PS, Luger TA, Schmelz M (2003) Proteinase-activated receptor-2 mediates itch: a novel pathway for pruritus in human skin. J Neurosci 23:6176-6180.

Sun Q, Xing GG, Tu HY, Han JS, Wan Y (2005) Inhibition of hyperpolarization-activated current by ZD7288 suppresses ectopic discharges of injured dorsal root ganglion neurons in a rat model of neuropathic pain. Brain Res 1032:63-69.

Sun YG, Chen ZF (2007) A gastrin-releasing peptide receptor mediates the itch sensation in the spinal cord. Nature 448:700-703.

Tuckett RP (1982) Itch evoked by electrical stimulation of the skin. J Invest Dermatol 79:368-373.

Tuckett RP, Wei JY (1987a) Response to an itch-producing substance in cat.I. Cutaneous receptor populations with myelinated axons. Brain Res 413:87-94

Tuckett RP, Wei JY (1987b) Response to an itch-producing substance in cat. II. Cutaneous receptor populations with unmyelinated axons. Brain Res 413:95-103.

Twycross R, Greaves MW, Handwerker H, Jones EA, Libretto SE, Szepietowski JC, Zylicz Z (2003) Itch: scratching more than the surface. QJM 96:7-26.

von Frey M (1922) Zur physiologie der juckempfindung. Arc Néerl Physiol 7:142-145.

Zylka MJ, Rice FL, Anderson DJ (2005) Topographically distinct epidermal nociceptive circuits revealed by axonal tracers targeted to Mrgprd. Neuron 45:17-25. 